\title{
Information About Ourselves from Ourselves: Young Users of Wearable Technologies in Secondary School
}

\author{
Ivana Matteucci \\ Department of Communication Science, Humanistic and International Studies (DISCUI), \\ "Carlo Bo" University of Urbino, Italy.
}

\begin{abstract}
Several researchers have recognized the value of self-tracking technologies used to personally obtain data about ourselves. The aim of the present study was to assess the barriers associated with the "technologies of existence", so-called wearables, including lack of knowledge of these devices, lack of information on their correct use, as well as difficulties regarding data integration and interpretation. To help to overcome these barriers we investigated a project involving two self-tracking activities in an Italian secondary school, performing a quantitative and qualitative analysis of the students using these technologies for educational purposes. Thanks to the project and its contextualized practical and theoretical activities, students were able to become "enhanced users" in terms of their knowledge, autonomy and awareness as regards wearable technologies. Our findings regarding the application of wearable technologies in a scholastic setting may also be step forward in addressing a well-known common pitfall of self-tracking: insufficient scientific rigor. Our quantitative and qualitative analysis showed how the use of wearable devices in educational settings had a range of beneficial effects, above all, eliciting satisfaction among students, but also yielding positive outcomes regarding the acquisition of scientific knowledge perceived both in terms of device applications and data interpretation. In conclusion, our findings may have broad implications in the future design and development of wearable technologies.
\end{abstract}

Keywords: Quantified Self, Wearable technologies, Secondary school, Scholastic setting

\section{Introduction}

Self-monitoring involves observing oneself (physiological states, athletic performance, well-being, behaviors, moods) in certain situations and carefully taking note of what is found. It often happens that one is aware of a problem, but unable to clearly define it. Being able to articulate a definition of the problem however can subsequently help us to have a greater control capacity. In fact, in self-monitoring we take on the role of "scientists", i.e. the phenomenon is analyzed by precisely and consistently recording our own observations. In the field of medicine and health, self-monitoring involves keeping track of the symptoms of a disease and their evolution, which a patient can do at home with the appropriate tools. In sociological terms, it is the observation and systematic control of one's behavior. The concept of self-monitoring is very old, but today smart technology makes the task of self-monitoring much simpler, translating every state and process of the self into numbers.

Self-knowledge through numbers has been defined as Quantified Self (Wolf, 2010), built on the idea that we lack the tools to make ourselves understand who we are, so to overcome our human limitations we need to enlist the help of machines and technology. In 2007, Gary Wolf and Kevin Kelly, editors of the magazine Wired, set up a blog called "Quantifiedself.com", which became a repository for anyone who wanted to share self-tracking practices. In 2010 Wolf spoke about the movement on TED@Cannes, and in May 2011, the first international conference on this topic was held in Mountain View, California. The Quantified Self (QS) has since become a movement to incorporate technology into data acquisition regarding aspects of a person's daily life (Kyoung et al., 2014) to improve daily functioning and wellness in terms of inputs (food consumption, air quality in their surroundings etc.), states (mood, arousal, blood oxygen levels etc.), and both mental and physical performance. In the United States in particular, this movement has created real communities of enthusiasts who, using wearable technologies, measure calories consumed, kilometers traveled, quality of sleep, and other minute aspects of their daily lives. 
But what exactly do we mean by "wearable technology" (Figure 1)? The term wearable technology refers to all technologies, designed around people's bodies and used as a natural support for their functioning. Sensory detection and monitoring of body signals, including those of an emotional nature, makes these technologies a valuable tool designed to meet the user's needs, while expanding their sensory capabilities as well. There are distinct categories of wearable devices: those that are capable of processing data, those that can communicate with a smart connected device (PC, smartphone or tablet) and those that can connect to the network independently without relying on other devices.

In the academic world several applications of self-tracking technologies in the field of health and wellbeing have been examined (Klasnja, Pratt, 2012; Swan, 2009). Many researchers conducting such investigations, in accord with what QS members claim, believe that thanks to the self-knowledge approach through data acquisition, it is possible for users to reflect on their activities, make discoveries about themselves, and use technology to make changes in their behavior (Bentley et al., 2013; Lin et al., 2006; Mamykina et al., 2008). Although researchers on the whole have reacted positively to these technologies, they have also discovered barriers to their adoption, including insufficient knowledge for an integrated and coordinated use of data, inadequate skills for an effective use of the devices and insufficient motivation (Li et al., 2010). Other researchers are critical of the commercialization of self-tracking, as they believe that the widespread use of data as a meta-social commentary on a person in his own social position can became the objective basis for a kind of static discrimination. "Disruptive developments are already appearing which show what a new taxonomy of sociality could look like in the future" (Selke, 2016). Some sociologists denounce the emergence of a new form of social and medical surveillance that arises from the merchandising of personal health-related opinions and health information produced and shared on the network by the users of self-monitoring devices (Lupton, 2012, 2014). Others fear the advent of overly accountable patients or users, who may therefore be considered "guilty" of their disease, illness or lack of physical and mental fitness (Morozov, 2013). In the field of health, American researchers (Piwek et al., 2016) point out that it is not yet clear how beneficial these technologies will be in the health field, as the huge amount of information and data collected can generate anxiety and confusion among users in general and patients.

From a commercial standpoint, according to the International Data Corporation (IDC, 2015) (https://www.idc.com/tracker/showproductinfo.jsp?prod_id=962), worldwide shipments of wearable devices reached 101.9 million in 2016, a 29.0\% increase over 2015. While most available apps focus on overall wellness, healthcare companies and professionals are increasingly interested in a broader use of these applications, removing barriers to a mainstream adoption of mHealth, especially in the areas of disease management and the promotion of healthy lifestyles. Although the wearable device market in Italy is slightly behind the US market, interest in this sector has been strong for years, and even Italian companies have begun producing wearable devices. Numerous reports, conversations and statements of interest regarding wearable devices from users themselves can be found on the Web. Indeed, a Wearable Technology Observatory (http://wearable.to/osservatorio/) has been set up with the aim of developing a kind of virtual laboratory for new wearable technologies that could monitor national and international projects. The market, which is undoubtedly growing according to the Observatory, has three major problems preventing it from really taking off: the price of wearables, which is still too high, lack of knowledge on the part of users, as well as device usability and the difficulty of data integration and interpretation.

For these devices to come fully into mainstream use, knowledge of wearables and people's ability to use them effectively must be enhanced. Moreover, the functions of these devices must be expanded seeking to develop those that have a high impact on everyday life and are simple to use. Indeed, the aim of this evolving sector is to develop wearable devices that are adapted to the user's lifestyle, moving away from the concept of a passive accessory to become a fundamental and personal part of our existence. Being ever present in the least invasive way is one of the distinctive features of wearable systems, which makes them different from laptops or tablets and contributes to their success among people of all ages.

\section{The project involving the use of wearable technologies in a secondary school}

Two scholastic interdisciplinary activities supported by wearables were analyzed. The first activity was called "Allena..menti" and involved the subjects of mathematics and physical education. The second was called "Mobil..mente" and involved the subjects of natural science and physical education. The first activity consisted in carrying out the "step test", an indirect test for the measurement of Vo2max, i.e. maximum oxygen consumption, by measuring changes in the heart rate. A heart rate monitor, $36-\mathrm{cm}$ high bench and metronome were used. During the physical education class, one student carried out the test, another monitored it, and a third entered the data into the computer. The data were then processed using an Excel spreadsheet. In math class, the data were then used to plot a graph through equations and the study of the line. Thus, 
thanks to the synergy between two subjects, the students learned how to perform a basic assessment test for sports and physical activity and how to interpret the results.

The second activity involved the study of heart rate variation and its relationship to exercise intensity. The goal was to study the cardiovascular system in general and, in particular, the concept of heart rate and its relationship to exercise intensity. The students were accompanied by their teacher on a walking or cycling route. During these activities three variables were monitored: the heart rate of the students, altitude and walking/cycling speed. The students were equipped with a heart rate monitor and a GPS device with an altimeter. The data collected along the route were then processed and recorded on a computer. Subsequently, using a specific software, the data were transformed into 3D graphics and used in physical education and natural sciences classes for the study of this biological parameter and its variations. It is interesting to note that the use of wearable technology devices covered both the practical part of the field, namely measurements with heart rate monitors and GPS devices equipped with altimeters, as well as the theoretical part, namely data processing using specific software and data analysis using computers performed in the classroom.

\subsection{Survey and study method (quantitative and qualitative)}

A questionnaire (Table 1) with seven questions was designed to evaluate the project results. In particular, we analyzed the following aspects: the interest, the knowledge of the devices and their applications, the level of satisfaction of students regarding the proposed activities, the attitude, their perceived level of autonomy in the use of technological devices and their awareness of the reasons for the use of such devices and the possibility of integrating wearable technologies into daily life.

The survey section regarding the interest, the knowledge and the satisfaction level of the participants consisted of three questions: 1. Did you find the activities practiced using wearables to be interesting? 2. In your opinion, did your knowledge of wearable devices and their data improve? 3. Are you totally satisfied with this experience? Students had to express their opinion choosing from a range of four options: Definitely No, No more than Yes, Yes more than No, Definitely Yes (Chiandotto e Gola method, 1999). The survey section regarding attitude and autonomy in the use of the wearable devices consisted of the following questions: 4 . Do you think that your attitude towards this technology has improved after the initial impact? 5. Would you be able to use the wearable device in question alone? The same range of options used in the previous set of questions was used here.

The results were largely positive (Figure 2). In particular, students report that they found the activities to be very interesting $(31 \%)$ or rather interesting $(51 \%)$. They claim to have seen an improvement in their knowledge of the devices in question $(42 \%)$, although some confusion persists $(26 \%)$. This is one of the first studies of its kind; hence, further research is clearly needed, and we must be cautious in drawing conclusions from a single investigation. However, the satisfaction level with the experience offered through the project was high for students. Students' attitudes towards wearable technologies improved after the initial impact, and most of them also gained real autonomy in the use of these devices, although a number of subjects remained dependent on the support of an expert (14\% and $28 \%)$. This finding highlights the difficulty of promoting students as active learners at school and the opportunity offered by experiences that go in the direction of learning how to use new technologies correctly and responsibly.

Students were also asked the following questions to determine whether they viewed the integration of technology into everyday life positively and assess the perceived prevailing aspects or functions of this application. 6. In general, technology is designed to improve our lives. Do you think these wearable technologies can improve our lives? 7. If yes, how? A Likert scale was used for question 7 with the following items:

\section{A. Improving our health (track blood pressure, track heart rate, log triggers that cause disease ...);}

B. Improving wellbeing (track exercise, track weight, log sleep, log food, log panic, log mood ...);

C. Offering new life experiences (explore new places, orient in contexts, satisfy curiosity, have fun, enjoy relationship ...).

The results from this part of the questionnaire are also very interesting. For most students, wearables can really improve our lives $(73 \%)$. But how? Students are particularly interested in the contribution from the field of wellbeing. Perhaps the high percentage of students (40\%) who chose Improving wellbeing can be accounted for by the fact that students carried out activities in the field of physical performance and fitness, during the project. The second highest percentage of students $(35 \%)$ indicated that wearables can improve our lives by Offering new life experiences. The relatively high percentage of 
students who chose this option was probably influenced by the young age of respondents for whom technology nowadays means curiosity, fun, sharing, even functionality, fitness and is less related to health (Figure 3, Figure 4). However, it is interesting to note that even though it was ranked third, Improving health was chosen by $25 \%$ of students. These findings are in agreement with world-wide figures that see wearables used mainly in the fields of fitness and wellbeing and less in the health field.

To complete our study, a qualitative survey, based on student interviews, was used to more effectively address three aspects related to the use of wearable technologies, namely knowledge, autonomy and awareness, and to discover any pitfalls related to their use.

\section{Knowledge - What did you learn?}

In the interview, most students stated that they had made some progress in terms of improving their knowledge of these technologies, their applications and in the reading and interpretation of data. Students emphasized above all the enjoyable nature of this way of acquiring knowledge as a kind of "learning by doing". Some students thus describe a process that involves learning about the devices and at the same time gaining confidence in their use. 1) At first I felt embarrassed because I wasn't familiar with this technology, then I learned to manage it, and it became easier. 2) It's amazing how many things we can learn about ourselves in this way, and it's not hard at all. The machine does almost everything, and you just have to go about your everyday life as if it weren't there. 3) It was also very interesting to read the data about ourselves and compare them to those of other classmates.

Some students stated that they were initially afraid of not being able to meet the performance requirements and of having their performance compared with those of classmates. 4) At first I was pretty worried about not providing the right data or not being able to do the work. How embarrassing in front of all my classmates! In fact, the use of these technologies that produce numerical data related to the subject in quantitative terms (Quantified-self) can generate performance anxiety in the subject, and fear of comparisons being drawn with others.

There may be a risk of losing sight of the sociality component (Maturo, 2014). However, it is interesting to note how in this case, the social component was called into play. Subsequently, subjects who yielded data uploaded and shared them on social platforms. 5) I can't wait to add this information about myself on my facebook profile, and then I want to talk about it with my coach and football teammates. In addition, the data collection and processing activities, although related to individual subjects, were carried out in a groups in which each student was assigned a specific task to be carried out in collaboration with other group members.

\section{Autonomy - How did you work?}

In the interview, students stated that they were fully engaged in this experience and felt freer, more active and more creative while learning. The conditions in which the activities were carried out made them practical and enjoyable, especially the fact that the contents were generated by the students themselves. 6) I felt that the data we were working on hadn't been taken from books, they had been created by us. It was very rewarding! 7) It seemed odd to me that those numbers concerned us, our bodies and our work. This made them more interesting in our eyes.

\section{Awareness - What has changed?}

From the students interviews a new approach to understanding technology emerges. It is undoubtedly more conscious, as it prompts reflection on how technology can be a simple mild tool for everyday life, but also a "powerful" means to be used carefully by an "improved" or rather, "properly equipped" user. 8) I want to recommend this tool to my grandfather who has heart problems, but I will have to evaluate it well. The risks could outweigh the benefits because having this device on him all the time would be a constant reminder of his illness. Besides, I don't know if he could figure out anything from the data. Finally, some hope that the project will be continued. 9) I have certainly learned useful and important things for my life. It would be nice to be able to do it again in the future at school.

Our quantitative and qualitative analysis shows how, the use of wearable devices as "learning environments" at school, is first of all, a rewarding experience for students, it also yields positive outcomes in terms of the acquisition of knowledge regarding both device applications and data interpretation, it increases perceived user autonomy and skills, also prompting reflection on the fundamental reasons for the introduction and implementation of these technologies in everyday life. In addition, the results of the qualitative analysis show that the initial impact of wearable technologies can generate anxiety 
and worry; however, such feelings are dispelled through the study and application of these devices. The users enhanced sense of autonomy, and confidence was confirmed throughout the entire device application process.

\section{Conclusions}

As school in general is the biggest engine for innovation, investing in it to implement the use of new technologies and to verify their effects can be a useful and far-sighted strategy. Indeed, this early exposure to wearables, provided at a young age, can also help subjects later as adults to avoid certain pitfalls associated with these technologies while at the same time enhancing their ability to reap the benefits that can be obtained from contextualized knowledge and proper use of these devices. School can become a research lab to introduce novel ideas regarding cutting edge devices and their features, to prompt reflection about technology, and to verify the usability of such technologies.

Our project has yielded positive results in terms of enhancing subjects' knowledge, autonomy and awareness in the field of wearable technologies. The development of "enhanced wearable users" could help to provide what is said to be lacking for the mainstream development of wearables: widespread dissemination of the technology which would help reduce costs, skills related to the reading and interpretation of data and the need for scientific rigor, contextualization and integration of the devices into everyday life. These results are to be understood not only quantitatively in terms of an increase in the production and dissemination of wearable technologies, but also in terms of an enhancement of the quality of their application and use. In addition, the present study lays the groundwork for further investigations of this kind with the aim of pursuing the desired wider application of wearables in the field of health and, at the same time, improving their application to other areas of life (well-being and other experiences) in which they are already widely used.

\section{References}

[1] Bentley, F. et al. (2013). Health Mashups: Presenting Statistical Patterns Between Wellbeing Data and Context in Natural Language to Promote Behavior Change. ACM Transactions on Computer-Human Interaction (ToCHI), 20(5): 1-27. doi: $10.1145 / 2503823$

[2] Klasnja, P., \& Pratt, W. (2012). Healthcare in the Pocket: Mapping the Space of Mobile-phone Health Interventions. J Biomed Inform 45(1): 184-98. doi: 10.1016/j.jbi.2011.08.017

[3] Kyoung, C.E. et al. (2014). Understanding Quantified Selfers' Practicies in Collecting and Exploring Personal Data. Proceeding of the SIGCHI Conference on Human Factors in Computing Systems, Toronto, ON, Canada: 1143-1152.

[4] Li, I., Dey, A., \& Forlizzi, J. (2010). A stage-based Model of Personal Informatics Systems. In Proceedings of the SIGCHI Conference on Human Factors in Computing Systems, Atlanta, Georgia, USA, April 10-15: $557-$ 566. doi: 10.1145/1753326.1753409

[5] Lin, J.J., Mamykina, L., Lindtner, S., Delajoux, G., Strub, H. (2006). Fish'n'Steps: Encouraging Physical Activity with an Interactive Computer Game. In Proceedings of the $8^{\text {th }}$ International Conference on Ubiquitous Computing, UbiComp '06, Orange County, CA, USA: 261-78.

[6] Lupton, D. (2014). The Commodification of Patient Opinion: the Digital Patient Experience Economy in the Age of Big Data. Sociology of Health and IIIness, 36(6): 856-69. doi: 10.1111/1467-9566.12109

[7] Lupton, D. (2012). M-Health and Health promotion: The Digital Cyborg and Surveillance Society. Social Theory and Health, 10(3): 229-244. doi:10.1057/sth.2012.6

[8] Mamykina, L., Mynatt, E., Davidson, P., Greenblatt, D. (2008). MAHI: Investigation of Social Scaffolding for Reflective thinking in Diabetes Management. In Proceedings CHI 2008, Health and Wellness, April 5-10, Florence, Italy: 477- 86.

[9] Maturo, A. (2014). "Vite misurate". II Quantified Self e la salute digitale, Sociologia della comunicazione, XXV (48): $60-67$.

[10] Morozov, E. (2013). To Save Everything, Click Here: Technology, Solutionism, and the Urge to Fix Problems that don't Exist, Penguin, London.

[11] Piwek, L., Ellis, D.A., Andrews, S., Joinson, A. (2016). The Rise of Consumer Health Wearables: Promises and Barriers. PLoS Med 13(2): e1001953. doi:10.1371/journal.pmed.1001953

[12] Selke, S. (Ed.) (2016). Lifeloggin: Digital Self-tracking and Lifelogging - Between Disruptive Technology and Cultural Transformation, Springer, Wiesbaden GmbH. 
[13] Swan, M. (2009). Emerging Patient-driven Health Care Models: An Examination of Health Social Networks, Consumer Personalized Medicine and Quantified Self-tracking. Int J Environ Res Public Health, 6(2): 492-525. doi: 10.3390/ijerph6020492

[14] Wolf, G. (2010). The Data-Driven Life, The New York Time Magazine, April 28. Available from http://www.nytimes.com/2010/05/02/magazine/02self-measurement-t.html?mcubz=3 [last accessed September $5,2017]$

\section{Tables and Figures}

\begin{tabular}{|l|c|c|c|c|}
\hline Questions & Definiteix No & No more than Yes & Yes more than No & Definiteix Yes \\
\hline $\begin{array}{l}\text { 1. Did you find the activities practiced using } \\
\text { wearabless to be interesting? }\end{array}$ & $4 \%$ & $12 \%$ & $51 \%$ & $31 \%$ \\
\hline $\begin{array}{l}\text { 2. In your opinion, did your knowledge of wearable } \\
\text { devices and theirdata improve? }\end{array}$ & $12 \%$ & $26 \%$ & $42 \%$ & $18 \%$ \\
\hline 3. Are you totally satisfied with this expenence? & $3 \%$ & $7 \%$ & $55 \%$ & $32 \%$ \\
\hline $\begin{array}{l}\text { 4. Do you think that your attitude towards this } \\
\text { technology has improved after the initial impact? }\end{array}$ & $13 \%$ & $15 \%$ & $49 \%$ & $21 \%$ \\
\hline $\begin{array}{l}\text { 5. Would you be able to use the wearable device in } \\
\text { question alone? }\end{array}$ & $14 \%$ & $28 \%$ & $46 \%$ & $11 \%$ \\
\hline
\end{tabular}

\begin{tabular}{|l|l|l|}
\hline $\begin{array}{l}\text { 6. In general, technology is designed to improve our lives. } \\
\text { Do you think these wearable technologies can improve our lives? }\end{array}$ \\
\hline 7 . If yes, how? (score: from 1-2-3) \\
\hline $\begin{array}{l}\text { Improving health } \\
\text { (cure a condition, distinguish healthy and unhealthy lifestyles ...) }\end{array}$ & track blood pressure, track heart rate, log triggers that cause diseases \\
\hline $\begin{array}{l}\text { Improving wellbeing } \\
\text { (performance, find balance, experience wellbeing ...) }\end{array}$ & trackexercise, track weight, log sleep, log food, log panic, log mood ... & \\
\hline $\begin{array}{l}\text { Offering new life experiences } \\
\text { (explore new places, orient in contexts, satisfy curiosity, have fun, } \\
\text { enjoy relationships ...) }\end{array}$ & track the connected self ... \\
\hline
\end{tabular}

Table 1. Questionnaire

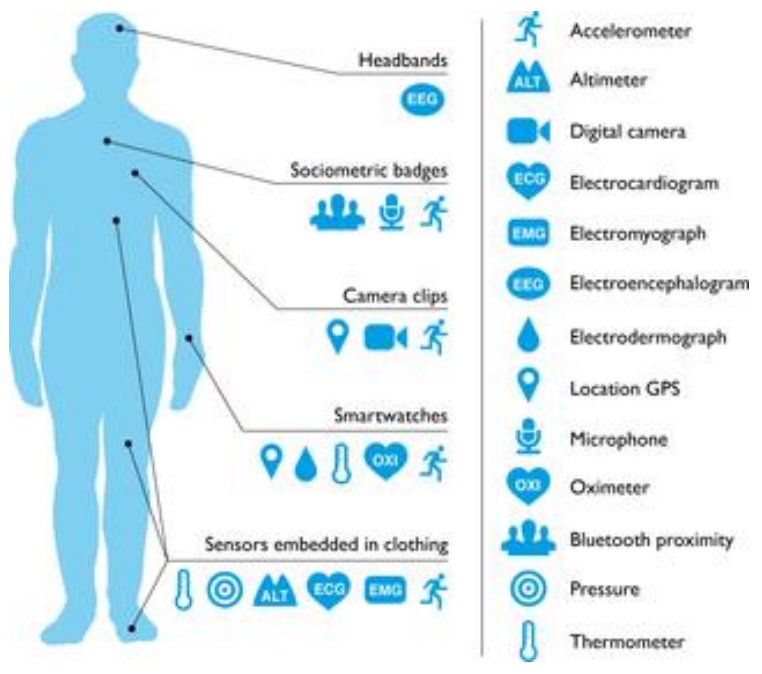


Fig. 1. The Rise of Consumer Health Wearables. Source: Piwek et al. (2016)

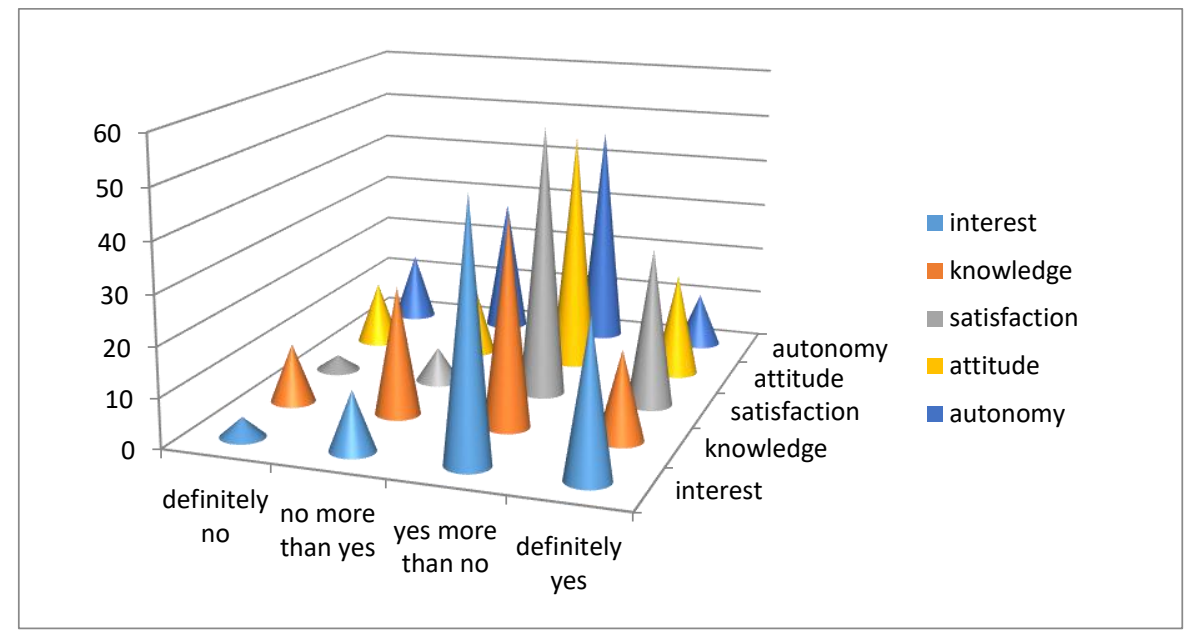

Fig. 2. Factors related to use of wearable technologies at school

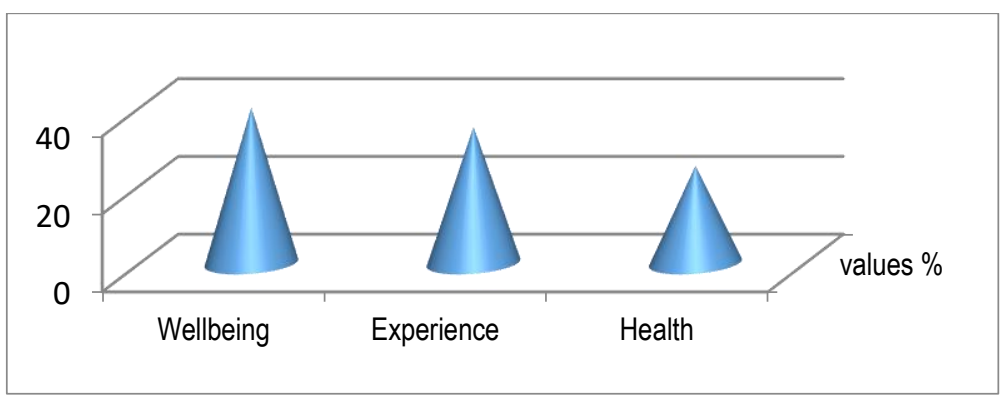

Fig. 3. The fields of application of wearables

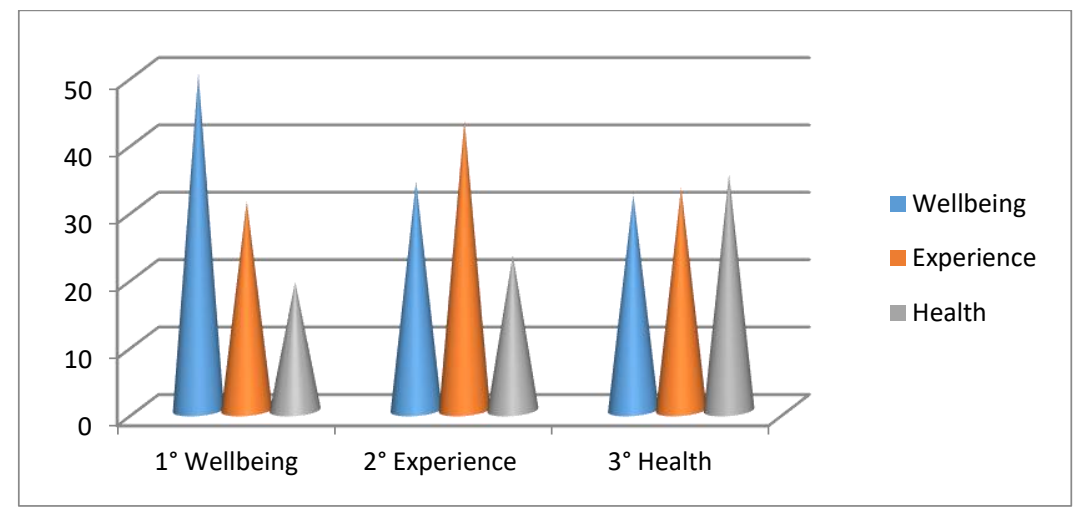

Fig. 4. A classification of the fields of application of wearables 


\title{
Identifying the Drivers of Food Security Based on Perception among Households in South Western Nigeria
}

\author{
Wasiu Olayinka FAWOLE \\ Department of Agricultural Economics, Faculty of Agriculture, Akdeniz University, Antalya, Turkey \\ Burhan ÖZKAN \\ Department of Agricultural Economics, Faculty of Agriculture, Akdeniz University, Antalya, Turkey
}

\begin{abstract}
Food insecurity has been considered lately as one of the developmental challenges facing developing nations particularly the sub-Saharan Africa that if not curtailed may have embarrassing consequences not only to the affected area but to humanity in general due to instability that may occur. This study aimed to identify those factors that influence food security and how they did to guide the relevant stakeholders in the design and implementation of food programmes. The study assessed food security of the households based on perception of heads/appointed representatives and logistic regression model to identify its drivers in respective households. The findings of the study revealed that majority of households investigated (60.2 percent) showed varying degrees of food insecurity and hunger while those living with moderate hunger were leading by 31.6 percent. Furthermore, logistic regression analysis results showed that eight of the ten explanatory variables such as income, access to credit and public health facilities among others as specified in the model significantly influenced the food security of the sampled households.
\end{abstract}

Keywords: identifying, drivers of food security, perception, households, South Western Nigeria

\section{Introduction}

Food security has been variously defined by various studies and stakeholders alike the latest of which was defined as "a situation that exists when all people, at all times, have physical, social and economic access to sufficient, safe and nutritious food that meets their dietary needs and food preferences for an active and healthy life" (FAO 2002). Also, FAO (2008) categorized food security into four dimensions; availability, accessibility, utilization and sustainability. Each of these dimensions are independent of each other suggesting that achievement of one does not guarantee the achievement another but the achievement of all dimensions are required to attain a state of food security within a population group. However, food insecurity in recent times has been identified as one of the key developmental challenges bedeviling the developing nations particularly the sub-Sahara African countries which could be attributed to many factors some of which the study is trying to examine using south western Nigeria as a reference group and taking into consideration the peculiarities of the affected population. According to the chairperson of World Food Summit held in 2002 and quote "...together with terrorism, hunger is one of the greatest problems the international community is facing...." (Clover 2003). Corroborating this assertion, James Morris, the then executive director of World Food Programme (WFP) in his address to the UN Security Council in December 2002 about Africa's food crisis and equally asserted that in addition to the problems of AIDS/HIV faced by people is another danger posed by food insecurity and hunger where about 38 million people in Africa alone faced imminent threat to their peace, security and stability which has since surged (WFP 2002). According to the latest reports published by the Food and Agricultural Organization (FAO) of the United Nations, food insecurity in the world had risen from 777 million in 2015 to 815 million in 2016 (FAO, 2017).

It is pertinent to note that every food programme requires the full assessment of the prevailing food insecurity among the target vulnerable group before meaningful interventions could take place. For example, food security can be achieved at national level by either self-production or sufficient import in case of lack of resources for self-production like land, climate and other environmental factors that may prevent growing of food crops and rearing of animals for animal protein while it 
can also be achieved by either self-production on family farms or purchase from the market (Fawole 2017). Several studies and investigations have been carried out in respect of determinants of food security in terms of socioeconomic and political characteristics with some coming up with several factors that were seen to influence the food security of groups of people. In the case of Nigeria, declining food production occasioned by neglect of agriculture in the face of growing population has grossly affected the fortunes of food security at national level in the country as a whole with spiral effects on the households who were always the most hit of the effects of food insecurity being the consuming units and are vulnerable to food shocks due to socioeconomic imbalances. For instance, the Nigerian population annual growth rate is estimated as 3.5 percent with accompanying 2.7 percent growth rate or less in agriculture which is largely insufficient to meet food needs of the entire population (NBS 2017).

This study became necessary in view of the fact that most food intervention programmes have not yielded the desired results in most African countries including Nigeria because they have failed to study what drive the food security among different population groups but have majorly relied on templates from other climes with different scenarios. In some cases, most of the implementing partners have been using what obtained in other regions to tackle the problem of food insecurity in Nigeria which has not been working at desired level. For instance, food programmes in the north eastern parts of the country where there have been humanitarian crises triggered by boko haram insurgency have exposed these lapses and confirmed that indeed majority of the implementing partners from international NGOs to UN agencies lacked clear knowledge and information on what drive the food security status of people particularly the vulnerable groups in a country as big as Nigeria with diverse sociopolitical and economic characteristics based on their own convictions and perceptions thus making it difficult to design appropriate food programmes of intervention.

\section{Material and methods}

This study was conducted in south western Nigeria by sampling 161 households using multistage random sampling technique. Primary data collected with the aid of structured questionnaires were used for this study. South West Nigeria was selected based on its strategic importance to food production in Nigeria and at a time all talks on food insecurity in Nigeria have been centered on North East due to insurgency problems there. Furthermore, food security status of the sampled households in the study area were computed based on perception of heads or other appointed representatives on prevailing food security situation in their respective households. This method is innovative in assessing food security of the households to avoid the criticisms based on shortcomings that have always associated with the traditional food indicators that have been used for the same purpose by different authors using various indicators.

\section{Food security based on perception of household heads/appointed representatives}

In assessing food security of the households based on this technique, the following questions were asked from the representatives of the households who were heads or designated individuals familiar with the food supplies and consumption in the households in each case and the responses were recorded and analyzed as follows;

\section{How best can you describe the food security situation in this household based on your perception?}

$$
\text { Food secure, FS }
$$

(ii.) Food insecure (without hunger), FIWH

(iii.) Food insecure (with moderate hunger), FIMH

(iv.) Food insecure (with severe hunger), FISH

\section{Factors affecting food security in the study area}

After getting the food security situation among households as described above, the drivers of food security among households were examined by using binary logistic regression model as specified subsequently. For the purpose of analysis, the dependent variable was household food security based on perception of household heads or other appointed representatives on food security situation in their respective households. In doing this, households who were food secure were marked 1 while those who showed varying degrees of food insecurity like food insecurity without hunger (FIWH), food insecurity with moderate hunger (FIMH) and food insecurity with severe hunger (FISH) were categorized as 0 for the sake of binary logistic regression analysis. This study followed the works of Gujarati and Porter (2009) and Abbas et al (2017). 


\section{Specification of the logistic regression model}

$\mathrm{L}_{i}=\ln \left(\frac{\mathrm{P}_{i}}{1-\mathrm{P}_{i}}\right)=\mathrm{Z}_{i}$

From the general model as specified in (1) above,

$Z_{i}=\beta_{0}+\beta_{i} X_{i}+\mu_{i}$

Where $i=1,2,3 \ldots 10$. The equation (1) above can thus be rewritten as;

$\mathrm{L}_{i}=\ln \left(\frac{\mathrm{p}_{i}}{1-\mathrm{P}_{i}}\right)=\beta_{0}+\beta_{\mathrm{i}} \mathrm{X}_{\mathrm{i}}+\mu_{\mathrm{i}}$

(Gujarati and Porter 2009 and Abbas et al 2017)

Dependent variable $=$ food security $($ food secure $=1$, food insecure $=0$ )

$X_{i}=$ explanatory variables as stated below;

Access to credit facilities (access $=1$, no access $=0$ ), access to public health facilities (access $=1$, no access $=0$ ), coping strategies (number of coping strategies used by household; $0-9$ ), gender status of the household head (Male $=1$, female $=0$ ), age of the household head (in years), marital status of the household head (married $=1$, otherwise $=0$ ), major occupation of the household head (farming $=1$, non-farming $=0$ ), non-food expenditure (in naira), household total monthly income (in naira), state of location of the household (Osun $=1$, Oyo $=0$ ).

\section{Results and Discussions}

\section{Results}

The major findings of the study revealed that majority of the households investigated showed varying degrees of food insecurity and hunger in some cases. However, 39.8 percent of the households were food secure based on perception of the household heads or other appointed representatives who answered questions on prevailing food security situation of the households in the study area. Also, in terms of what drive the food security among households in the study area, eight of the ten explanatory variables specified in the logistic regression model significantly influenced the food security of the households.

\section{Discussions}

The results of the analysis of food security status of households in the study area as shown on Table 1 reveal that food insecurity in the study area is not only high but approaching a dangerous dimension considering the percentage of households that still live with varying degrees of hunger despite previous interventions aimed at halting the trend among the vulnerable population. The implication of these findings as shown on Table 1 is that based on the perception of the household heads and other appointed representatives of the households, majority of the households agree that they are consuming less than required quantity and quality of their preferred food items necessary for their active and healthy living and as such will require external interventions that could ensure provision of foods for immediate consumption or actions that could boost their income generation through sustainable livelihoods that would enable them to acquire their preferred foods for active and healthy living as recommended by United Nations.

Table 1: Classification of households into food security statuses

\begin{tabular}{lll}
\hline Food security status & Number of households & Percentage \\
\hline FS & 64 & 39.8 \\
FIWH & 43 & 26.7 \\
FIMH & 51 & 31.6 \\
FISH & 3 & 1.9 \\
\hline Total & 161 & 100 \\
\hline
\end{tabular}


Field survey, 2016; FS = Food secure, FIWH = Food insecure without hunger, FIMH = Food insecure with moderate hunger, FISH = Food insecure with severe hunger

Furthermore, this study as earlier hinted sought to identify those factors that influenced the food security situation of the households and these findings are as shown on Table 2 subsequently. Also, the respective influences of the specified explanatory variables on the food security status of households are as highlighted shortly;

\section{Accessibility to credit facilities by household head}

The slope of coefficient of access to credit facilities by household head is 1.475 with positive sign and significant $(p<0.1)$ suggesting that having access to credit facilities by household head increases the weighted log of odds in favour of food security in the household by 1.475. Again, based on the odds ratio as depicted on Table 2 subsequently, the results implied that when a household head had access to credit facilities, the odds of being food secure is 4.37 times more than when otherwise. In other words, when a household head had access to credit facilities, the probability of being food secure is 0.29 (29 percent) more than when otherwise when other factors are held constant. These findings are consistent with findings of Amaza et al (2008), Muche et al (2014) and Arene and Anyaeji (2010) but in contrast with those of Babatunde et al (2007a) and Babatunde et al (2007b).

\section{Accessibility to public health facilities}

The slope of coefficient of accessibility to public health facilities by household members is 1.311 with positive sign and significant $(p<0.05)$ suggesting that having access to public health facilities increases the weighted log of odds in favour of food security in the household by 1.311. Again, based on the odds ratio as depicted on Table 2 subsequently, the results implied that when a household had access to public healthcare facilities, the odds of being food secure is 3.71 times more than when the situation is otherwise. In other words, when the household had access to public healthcare facilities, the probability of being food secure is 0.19 (19 percent) more than when the situation is contrary. These findings are well in line with a priori expectation especially considering the utilization dimension of food security but in contrast with the findings of Obayelu (2012) that reported contrary.

\section{Coping strategies utilized by households during food shortages}

The coping strategies $(0-9)$ employed by households during food shortage gave a slope of coefficient of -1.312 , a negative sign and highly significant $(p<0.01)$ suggesting that with every one-unit increase in the number of coping strategies adopted by household, the weighted log of odds in favour of food security decreases by 1.312. Again, based on the odds ratio as depicted on Table 2 subsequently, the results implied that when the number of adopted coping strategies increased by 1 , the odds of being food secure decreased by a factor of 0.27 . In other words, when the number of adopted coping strategies by household during food shortage increased by one-unit, the probability of being food secure decreased by 0.20 (20 percent) when other factors are held constant. These findings are in line with a priori expectation which stated that food security level decreases with increasing number of adopted coping strategies employed by household just as a household that is completely food secure does not use any coping strategy due to food sufficiency being experienced in such household. These results are in congruent with Okwoche and Benjamin (2012).

\section{Age of the household head}

The slope of coefficient of age household head is 0.063 , with a positive sign and significant $(p<0.05)$ suggesting that for every one-year increase in the age of household head, the weighted log of odds in favour of food security increases by 0.063. Again, based on the odds ratio as depicted on Table 2 subsequently, the results implied that when the age of the household head increases by a year, the odds of being food secure also increases by a factor of 1.06 (107 percent). In other word, when the age of a household head increases by a year, the probability of being food secure increases by 0.0096 ( 0.1 percent) when other factors are held constant. These findings are in line with a priori expectation that household headed by old person tends to show higher degree of food security because they have among other things relatively more years of working experience especially those who are working with government and other paid jobs and this in most cases translates to more income accruable to the household on one hand and food security on the other hand. These findings are in congruent with those of lorlamen et al (2013), Obayelu (2012) and Mitiku et al (2012) which reported similar findings but however in contrast with Babatunde et al (2007a) and Babatunde et al (2007b) that reported contrary findings. 


\section{Marital status of the household head}

The slope of coefficient of marital status of household head is -3.643 , with a negative sign and highly significant $(p<0.01)$ suggesting that with a household being headed by a married person, the weighted log of odds in favour of food security decreases by 3.643. Again, based on the odds ratio as depicted on Table 2, the results implied that when a household is headed by a married person, the odds of being food secure 0.03 ( 3 percent) lesser than when otherwise. In other word, when a household is headed by a married person, the probability of being food secured is 0.72 (72 percent) lesser than when otherwise when other factors are held constant. These results are in congruent with the findings of Obayelu (2012) which reported that household headed by married persons showed less food security than when the situation is contrary which might have been as a result of fewer people or in some cases only one person in a household when the head is not married.

\section{Major occupation of the household head}

The slope of coefficient of major occupation of household head is -1.051 . The negative sign is significant $(p<0.1)$ suggesting that having farming as major occupation of household head decreases the weighted log of odds in favour of food security in the household by 1.051. Again, based on the odds ratio as depicted on Table 2 subsequently, the results implied that when the major occupation of a household head is farming, the odds of being food secure is 0.35 times less than when the major occupation of household head is non-farming. In other word, when the major occupation of a household head is farming, the probability of being food secure is 0.16 (16 percent) less than when the major occupation is nonfarming when other factors are held constant. These findings are in agreement with Okwoche and Benjamin (2012) which reported similar findings but however in contrast with the findings of Omotesho et al (2006) and Obayelu (2012) which held that farming as major occupation headed households were more food secure. Households headed by someone with nonfarming as major occupation could possibly have shown more food security than ones headed by someone with farming as major occupation due to disparity in income as those with non-farming major occupation might have had access to different varieties of food items for his households unlike the one headed by farmer who relied solely on seasonal and unsustainable food supplies from family farm.

\section{Total monthly income of household head (Naira)}

The slope of coefficient of total monthly income of the household head is $5.5 \mathrm{e}-06$, with a positive sign and significant $(p<$ 0.05 ) suggesting that with every one-naira increase in total household monthly income, the weighted log of odds in favour of food security increases by 5.5e-06. Again, based on the odds ratio as depicted on Table 2 subsequently, the results implied that when the total household income increased by 1 naira, the odds of being food secure also increased by a factor of 1 meaning that the household food security and total household income change in the same proportion and positive direction. Similarly, when the income of a household increased by 1 naira, the probability of household being food secure also increased by 0.000085 percent when other factors are held constant. These findings are consistent with those of Mitiku et al (2012) and Arene and Anyaeji (2010) which also reported significant and positive relationship between household income and food security in their respective studies but in contrast with the findings of Kuwenyi et al (2014) and Ndhleve et al (2013) which reported otherwise.

\section{State of location of the household (Osun or Oyo)}

The slope of coefficient of state of location of household is -1.28 , with a negative sign and significant $(p<0.05)$ suggesting that with household located in Osun, the weighted log of odds in favour of food security decreases by 1.28 . This is in contrast to what obtained in food security according based on food expenditure. This is unconnected with lower cost of living in Osun state as compared with what obtained in Oyo state. This is however not the case as seen here with food security based on self-report. Again, based on the odds ratio as depicted on Table 2 subsequently, the results implied that that when a household is located at Osun, the odds of being food secure is 0.278 less than when the household is located in Oyo. In other word, when a household is located in Osun, the probability of being food secure is 0.19 less than when located in Oyo.

Generally, the results showed that all the explanatory variables had marginal effects on the food security status of the households considering their relatively low $p-$ value $(p<0.001)$. The model is considerably fit going by the values of Pseudo $R^{2}$ and percentage of correct predictions (count $R^{2}$ ) of 0.560 and 86.3 respectively as shown on Table 2 . The Hosmer-Lemeshow chi (8) value is 9.81 which showed that the model correctly fits the data. 
Table 2: Results of Logit analysis identifying drivers of food security

\begin{tabular}{|c|c|c|c|c|c|c|}
\hline Variables & Coefficient & SE & $z$ - stat & $p>|z|$ & Odds ratio & ME \\
\hline Constant & 0.2476 & 1.6615 & 0.15 & 0.882 & - & - \\
\hline +Access to credit facilities & $1.4749^{*}$ & 0.8660 & 1.70 & 0.089 & 4.3706 & 0.2850 \\
\hline +Access to public health facilities & $1.3112^{\star *}$ & 0.6202 & 2.11 & 0.035 & 3.7106 & 0.1949 \\
\hline Coping strategies utilized & $-1.3117^{\star \star \star}$ & 0.2162 & -6.07 & 0.000 & 0.2694 & -0.2002 \\
\hline +Gender & 2.2734 & 1.4464 & 1.57 & 0.116 & 9.7123 & 0.1818 \\
\hline Age of the household head & $0.0627^{* *}$ & 0.0309 & 2.03 & 0.042 & 1.0647 & 0.0096 \\
\hline +Marital status of household head & $-3.6433^{\star * \star}$ & 1.3962 & -2.61 & 0.009 & 0.0262 & -0.7195 \\
\hline +Major occupation of H/head & $-1.0505^{*}$ & 0.6298 & -1.67 & 0.095 & 0.3498 & -0.1612 \\
\hline Non-food expenditure shares & 0.00001 & $8 \mathrm{E}-06$ & 1.37 & 0.172 & 1.0000 & 1.7E-06 \\
\hline Total household monthly income & $5.5 \mathrm{E}-06^{* *}$ & $2.8 \mathrm{E}-06$ & 1.97 & 0.049 & 1.0000 & $8.5 \mathrm{E}-07$ \\
\hline +State of location of the household & $-1.2800^{* *}$ & 0.5911 & -2.17 & 0.030 & 0.2780 & -0.1922 \\
\hline Log likelihood & -47.58 & \multicolumn{2}{|c|}{ No of observations } & 161 & Akaike info & 0.728 \\
\hline $\operatorname{LR}_{\text {chi² }}(10)$ & 121.22 & \multicolumn{2}{|c|}{ Mean marginal effects } & 0.188 & Schwarz & 0.938 \\
\hline Hosmer-Lemeshow chi² (8) & 9.81 & \multicolumn{2}{|c|}{ Prob. $>\operatorname{chi}^{2}$ (p-value) } & 0.0000 & & \\
\hline Percentage of correct predictions & 86.3 & \multicolumn{2}{|c|}{ Pseudo $\mathrm{R}^{2}$} & 0.5602 & & \\
\hline
\end{tabular}

Source: Estimates of the Logit analysis results for field survey, 2016; SE: Standard Error; ME: Marginal effects; (+) represents dummy variables (0 or 1); Dependent variable: Food security; ${ }^{* *}$ Significant at $1 \%$ level, ${ }^{*}$ Significant at $10 \%$ level.

\section{Conclusions and recommendations}

From the findings of this study, it can be concluded that food insecurity in the study area is a growing concern as revealed by findings of similar studies conducted previously in the study area. The methodology used was an innovative assessment technique that is gaining ground in the assessment of food security in developing countries going by its relative simplicity particularly in terms of affordability as most developing countries lack accurate and reliable data for assessing food security. In order to overcome the problem of food insecurity and hunger in Nigeria, all hands must be on deck to addressing various factors that significantly affect the food security among households as identified by these findings by taking into consideration how each variable affects food security of the households. As an illustration to guide the stakeholders in foodsub sector, there must be policies and programmes that guarantee economic access to resources of production like credit facilities to enable the households have unhindered access to their preferred foods for their active and healthy living. Also, provision must be made for qualitative healthcare facilities that will be accessible and affordable considering the role it plays in maintaining food security particularly the utilization dimension of it which also requires good sanitation and hygiene. Furthermore, there must be adequate provision for the married and those households with more members to feed on through some social protection programmes as it is done in developed countries which could be in form of creation of employment opportunities for the young members with a view to ensuring additional income to the households to guarantee economic access to food items of their choice. Again, the major occupation of households was seen to influence food security of households negatively with households headed by someone whose major occupation is non-farming showing more food security. What this implies is that there should be policies that will encourage diversification of livelihoods among households particularly farming households whose major source of income is farming which is largely rain-fed in most African countries and mostly at subsistence level thus may not be able to sustain those who depend on it for their source of income and food round the year owing to post-harvest loss due to lack of storage facilities and other factors alike. The income as expected influenced food security of the households positively with food security increasing with income among households which could be sustained by recommendations earlier made with regards to diverse and sustained livelihoods. Finally on the state of location of households either in Osun or Oyo, it is suggested that a comprehensive and holistic assessment of food security is carried out across the geopolitical zones particularly in the whole of south west with a view to compare and contrast the food security across states and come up with policy integration that will enable the states compare notes particularly on agriculture or other income generating activities to enable the most food insecure states 
embrace policies and programmes of most food secure states especially in the area of agricultural policy that deals with food production and distribution systems.

\section{References}

[1] Abbas, T., Ali, G., Adil, S.A., Bashir, M.K., \& Kamran, M.A. (2017). Economic analysis of biogas adoption technology by rural farmers: The case of Faisalabad district in Pakistan. Renewable Energy, 107, 431 - 439.

[2] Amaza, P. S., Adejobi, A. O. and Fregene, T. (2008), "Measurement and determinants of food insecurity in North East Nigeria: Some Empirical Policy Guidelines", Journal of food, Agriculture and Environment. Vol. 6 No. 2, pp. 92-96.

[3] Arene, C.J. and Anyaeji, R.C. (2010), "Determinants of Food Security among Households in Nsukka Metropolis of Enugu State of Nigeria", Pakistan Journal of Social Sciences (PJSS), Vol. 30 No. 1, pp. 9-16.

[4] Babatunde, R. O., Omotesho, O.A. and Sholatan, O. S. (2007a), "Socio-economics Characteristics and Food Security Status of Farming Households in Kwara State, North Central Nigeria", Pakistan Journal of Nutrition, Vol. 6 No. 1, pp. 49-58

[5] Babatunde, R.O., Omotesho, O.A. and Sholotan, O.S. (2007b), "Factors Influencing food security Status of rural farming households in North Central Nigeria, Agricultural Journal, 2 (3), pp. 351-357

[6] Clover, J. (2003), "Food Security in Sub-Saharan Africa", African Security Review, Vol. 12 No. 1, pp. 5-15.

[7] FAO (2002), "The State of Food Security and Nutrition in the World 2017, Rome", Available online at: http://www.fao.org/3/aI7695E.pdf

[8] FAO (2008), "An introduction to basic concepts of food security", EC-FAO Food security Programme, available online at: http://www.foodsec.org/docs/concepts_guide.pdf

[9] FAO (2017), "The State of Food Insecurity in the World 2001, Rome", Available online at: www.fao.org

[10] Fawole, W.O. (2017), "Assessment of food security situation among households in south western Nigeria Post-MDGs era", $\mathrm{PhD}$ Dissertation, Unpublished

[11] Gujarati, D. N. and Porter, D.C. (2009), "Basic Econometrics, $5^{\text {th }}$ edition, McGraw-Hill, New York, 2009

[12] Iorlamen, T.R., Abu, G.A. and Lawal, W.L. (2013), "Comparative Analysis on Socio-economic Factors between Food Secure and Food Insecure Households among Urban Households in Benue State, Nigeria", Journal of Agricultural Science, Vol. 4 No. 2, pp. 63-68.

[13] Kuwenyi, S, Kabuya, F.I and Masuku, M.B. (2014), "Determinants of Rural Households' Food Security in Shiselweni Region, Swaziland: Implications for Agricultural Policy", IOSR Journal of Agriculture and Veterinary Science (IOSR-JAVS). Vol. 7, Issue 11 Ver. III, pp. 44-50.

[14] Mitiku, A., Fufa, B. and Tadese, B. (2012), "Analysis of Factors Determining Households Food Security in Pastoral Area Oromia Region, Moyale District, in Ethiopia", International Journal of Agricultural Science, Research and Technology, Vol. 2, No. 3, pp. 105-110, Available online at: http://journals.iau.ir/article_517520_6a416b6674ddf60742bac6e7f10b6167.pdf.

[15] Muche, M, Endalew, B. and Koricho, T. (2014), "Determinants of Household Food Security among Southwest Ethiopia Rural Households", Food Science and Technology Vol. 2 No. 7, pp. 93-100, available online at: http://www.hrpub.org/download/20150101/FST1-11102511.pdf, doi: 10.13189/fst.2014.020701.

[16] Ndhleve, S., Musemwa, L. and Zhou, L. (2013), "Household food security in a coastal rural community of South Africa: Status, causes and coping strategies", African Journal of Agriculture and Food Security, Vol. 1 No. 1, pp.15-20.

[17] Obayelu, A.E. (2012), "Households' food security status and its determinants in the North-Central Nigeria", Journal of Food Economics, Vol. 9 No. 4, pp. 241-256. Available online at: http://dx.doi.org/10.1080/2164828X.2013.845559 doi: 10.1080/2164828X.2013.845559

[18] Okwoche, V.A. and Benjamin, C.A. (2012), "Analysis of food security situation among Nigerian rural farmers", International Journal of Biological, Biomolecular, Agricultural, Food and Biotechnological Engineering, Vol. 6 No. 12, pp. 1-5

[19] Omotesho, O.A., Adewumi, M.O, Muhammad-Lawal, A. and Ayinde, O.E. (2006), "Determinants of Food Security among the Rural Farming Households in Kwara State, Nigeria", African Journal of General Agriculture, Vol. 2 No.1, pp. 7-15.

[20] World Food Programme, (2002), "World Food Summit", 3 December 2002, available online at: pp. 2 